\title{
Effects of organic acid pretreatment on microstructure, functional and thermal properties of unripe banana flour
}

\author{
Tonna A. Anyasi ${ }^{1}$ - Afam I.O. Jideani ${ }^{1}$ (D) Godwin R.A. Mchau ${ }^{2}$
}

Received: 8 February 2016/Accepted: 11 July 2016/Published online: 20 July 2016

(c) The Author(s) 2016. This article is published with open access at Springerlink.com

\begin{abstract}
Starch availability has been implicated in unripe matured banana (Musa species), which when processed yields flour suitable for application in low gluten and composite wheat formulations. Unripe Musa species: Williams, Luvhele, Mabonde and Muomva-red obtained from fruit bunch were pretreated with ascorbic, citric and lactic acids, processed into $50 \mathrm{~g}$ of flour and characterised for their functional and thermal properties. Scanning electron microscope of unripe banana flour (UBF) showed varying micrographs of flour, with polygonal for Luvhele, oval for Mabonde, elongated for Muomva-red and between polygonal and spherical for Williams. The bulk density of UBF samples was within the range of $0.66-0.84 \mathrm{~g} / \mathrm{mL}$ for all organic acid pretreatment while citric acid pretreated UBF had the least browning index. Significant difference $(p<0.05)$ was recorded in swelling power with no significant difference in water solubility index except for Mabonde UBF. Thermal properties showed single
\end{abstract}

Electronic supplementary material The online version of this article (doi:10.1007/s11694-016-9376-2) contains supplementary material, which is available to authorized users.

Tonna A. Anyasi

tonna.anyasi@univen.ac.za; tonna.anyasi@gmail.com

Afam I.O. Jideani

Afam.Jideani@univen.ac.za

Godwin R.A. Mchau

ainamensa.mchau@univen.ac.za

1 Department of Food Science and Technology, School of Agriculture, University of Venda, Thohoyandou, Limpopo Province 0950, South Africa

2 Department of Horticultural Sciences, School of Agriculture, University of Venda, Thohoyandou, Limpopo Province 0950, South Africa endothermic transition for all UBF samples at various pretreatment concentration. The onset temperature $(\mathrm{To})$ of UBF ranges from 49.82 to $65.59^{\circ} \mathrm{C}$, peak temperature $(T p)$ from 60.11 to $76.71{ }^{\circ} \mathrm{C}$, conclusion temperature $(T c)$ from 70.36 to $94.16^{\circ} \mathrm{C}$ and enthalpy of gelatinization $(\Delta H)$ from 2.61 to $32.24 \mathrm{~J} / \mathrm{g}$. Short amylopectin chains present in starch of UBF was attributed to low $T o, T p, T c$ and $\Delta H$ values recorded for Mabonde cultivar, while the contribution of heat-moisture treatment rather than organic acid pretreatment of UBF samples was attributed to different gelatinization and transition temperatures recorded for all cultivars examined.

Keywords Musa species - Banana flour - Functional properties · Microstructure $\cdot$ Pretreatment . Thermal properties

\section{Introduction}

Banana, when harvested at its unripe green stage of maturity contains starch almost equivalent to the starch content of endosperm of corn and pulp of white potato [1, 2]. As reported by Langkilde et al. [3] and Bello-Perez et al. [4], banana has found application in both nutritional and nutraceutical use. The fruit has also been implicated as a huge source of lignin, cellulose, hemicellulose and starch when harvested at its green stage of unripeness. Therefore, utilization of the fruit at this stage of maturity by processing into flour will increase its functionality. Upon peeling, banana undergoes several microbial and biochemical reactions [5]. One of such reactions is enzymatic browning: a biochemical reaction which occurs during peeling of fruits with the undesirable effects on colour and flavour of the processed fruit. Organic acids which are 
defined as carbon containing compounds with weak acidic properties and sometimes synthesized by plants $[5,6]$, can be employed in the reduction of enzymatic activities and preservation of fruits. The increasing use of organic acids such as citric, ascorbic $[5,7,8]$, acetic, fumaric, sorbic and benzoic acid [6, 9], among others in food processing, is due to the fact that these weak carbon containing acids are naturally derived.

Bello-Perez et al. [4] reported that unripe banana can be used in the production of functional flour due to its high levels of starch and non-starch polysaccharide present especially at the fruits' green state of unripeness. Similarly, the works of Juarez-Garcia et al. [10] showed that bread produced using unripe banana flour indicated higher levels of dietary fibre, resistant starch and insoluble digestible fraction than bread produced using wheat flour. According to Zhang et al. [1] functional properties of solubility index and swelling power can be used in determining the level of interaction between starch chains of flour granules while the bulk index and colour indices are applied in packaging and colour stability of flour.

Internal flour microstructure is also used as indicative characteristics for profiling flour and starch from different food produce based on the observed structure and shapes [11]. Flour microstructure plays a significant role in texture, flavour, storage and even nutritional properties of processed foods [12]. Microscopy techniques such as light microscopy, florescence microscopy and scanning electron microscopy (SEM) are employed in the study of the internal structure of raw and processed food commodities [13]. SEM on its part can be applied in the determination of the surface morphology and internal structure of foods depending on the preparation technique [14]. Observed shapes and size are dependent on a combination of factors which include food source, amylose and amylopectin content [15] as well as environmental conditions during cultivation [16]. Mainly found in roots, tubers, seeds, stems, fruits and even leaves, flour and starch granules are produced in separate amyloplasts either individually or in compound forms [17]. Variations that occur in these granules therefore provide sufficient information for the characterization of the food produce [18].

Numerous processing factors such as starch concentration, cooking time and temperature, rate of heating and cooling and shear during cooking, cooling and filling have been implicated in influencing the physical structures and distribution of starch in a food system. Other factors such as botanical source, temperature, water activity as well as the presence of protective or antagonistic ingredients are also said to affect changes during storage and processing of food produce [19]. Therefore, the functional and thermal properties of flour as well as the variations that exist in flour microstructure can be investigated. This will increase the application of unripe banana flour in baking, packaging, transportation and consumer acceptability of the plant based produce as well as the in cultivar characterization among banana varieties. This research therefore seeks to investigate the effect of pretreatment on thermal, functional properties and microstructure of unripe banana flour (UBF) obtained from commercial and non-commercial banana cultivars in Limpopo Province of South Africa.

\section{Materials and methods}

\section{Fruit samples and pretreatment}

In conducting this study, four unripe banana (Musa spp) cultivars: Luvhele (Musa ABB), Mabonde (Musa AAA), Muomva-red (Musa balbisiana cv Muomva-red) and (Musa acuminita $\mathrm{cv}$ Williams) at stage 2 of unripeness [20] were used. The non-commercial banana cultivars: Luvhele, Mabonde and Muomva-red were obtained from home communities in Thohoyandou, Limpopo Province of South Africa. A commercial banana cultivar (Musa acuminita cv Williams) was used as a control in this study. During the collection of samples, the land owners gave specific permissions for obtaining the banana cultivars from their home gardens and farms. In some instances, the banana cultivars were purchased from these home gardens/farms. The experiment was not conducted in the field but cultivars obtained were transported to the laboratory at the University of Venda for onward analyses. Endangered species were not used for this experiment but rather the study had a primary focus on reducing postharvest waste. This was primarily the case as the noncommercial cultivars used are often left to rot after harvest and wasted due to underutilization. Three pretreatments which are generally regarded as safe (GRAS) organic acids: ascorbic, citric, and lactic acids were used at three different concentrations of 10,15 and $20 \mathrm{~g} / \mathrm{L}$ for individual cultivars before milling to flour.

\section{Unripe banana flour production}

Pulp of unripe banana fruit from all four cultivars were cut to $4 \mathrm{~mm}$ size and pretreated with GRAS organic acids at concentrations of 10,15 and $20 \mathrm{~g} / \mathrm{L}$ for $10 \mathrm{~min}$. After pretreatment, pulp was drained by filtering to remove organic acids and spread on oven pans covered with foil paper. Fruit pulp was oven dried at $70{ }^{\circ} \mathrm{C}$ for $12 \mathrm{~h}$ using an air oven dryer. Oven dried pulp was milled using a miller (Retsch ZM 200miller, Haan, Germany) at 16,000 rpm for 2 min to obtain banana flour. The banana flour was then sealed in low density ethylene plastic bags and stored at $-20{ }^{\circ} \mathrm{C}$ until further analysis was conducted. 


\section{Colour analysis}

Colour profile of UBF was determined using the Hunterlab LabScan XE Spectrophotometer CIELAB colour scale with the parameters $L^{*} a^{*} b^{*} . L^{*}$ indicates lightness, $0-100$ with 0 representing black and 100 representing white. Coordinate $a^{*}$ corresponds to red (positive values) and green (negative values) while $b^{*}$ corresponds to yellow (positive values) and blue (negative values). The methods of Rodriguez-Aguilera et al. [21] and Mohapatra et al. [22] were used in the determination of whiteness index (WI) and browning index (BI) of UBF samples obtained from $L * a * b *$ values using Eq. (1-3).

$\mathrm{WI}=100-\sqrt{(100-L)^{2}+a^{2}+b^{2}}$

$\mathrm{BI}=100 \times \frac{\mathrm{x}-0.31}{0.71}$

where $\mathrm{x}=\frac{(\mathrm{a} *+1.75 \mathrm{~L})}{5.645 L+\mathrm{a} *-3.012 \mathrm{~b} *}$

\section{Bulk density}

The methods of Krishnan et al. [23] as well as Oladele and Aina [24] were used with slight modification in the determination of bulk density of samples. Approximately $25 \mathrm{~g}$ flour sample was placed in a $50 \mathrm{~mL}$ measuring cylinder. Tapping of the measuring cylinder containing flour sample was done continuously until no visible decrease in volume was observed. Final values of bulk density were calculated using Eq. (4) as weight of flour (g) per flour volume $(\mathrm{mL})$.

Bulk density $=\frac{\text { weight of UB flour }}{\text { volume of UB flour after tapping }}$

\section{Swelling power}

Approximately $1 \mathrm{~g}$ of flour was mixed with $10 \mathrm{~mL}$ of distilled water in a centrifuge tube and heated at $80{ }^{\circ} \mathrm{C}$ for 30 min while shaking continuously. The tubes were removed and cooled to room temperature. Upon cooling, samples were centrifuged at $2200 \mathrm{rpm}$ for $15 \mathrm{~min}$. The supernatant was decanted and weight of the puree was then determined. Swelling power $(\mathrm{g} / \mathrm{g})$ was calculated using Eq. (5).

Swelling power $(\mathrm{g} / \mathrm{g})=\frac{\text { weight of paste }}{\text { weight of dry flour }}$

\section{Water solubility index (WSI)}

The supernatant obtained from the determination of the swelling power was decanted in a pre-weighed evaporation dish and dried to constant weight in the oven. WSI was obtained using Eq. (6).

$$
\begin{aligned}
& \text { WSI }(\mathrm{g} / \mathrm{g}) \\
& =\frac{(\text { weight of dish }+ \text { dried supernatant })-\text { weight of dish }}{\text { weight of dried sample }}
\end{aligned}
$$

\section{Scanning electron microscope of unripe banana flour (UBF)}

Imaging of unripe fruit flour was conducted using a Leo ${ }^{\circledR}$ 1430VP scanning electron microscope (SEM). Prior to imaging, flour samples were mounted on a stub with double sided carbon tape. UBF samples were then coated with thin layer of gold in a Bal-tec MED-020 Coating System to make flour surface electrically conducting. SEM revealed the microstructure of flour of all four banana cultivars. Beam conditions during surface analysis were $7 \mathrm{kV}$ and approximately $1.5 \mathrm{nA}$, with a spot size of $150 \mathrm{~mm}$ and a magnification of $1000 \mathrm{X}$.

\section{Thermal analysis of UBF}

The gelatinization behaviour of UBF obtained from different banana cultivars was analyzed using a differential scanning calorimeter (DSC, DSC 4000, Perkin-Elmer, Shelton, CT, USA), according to the methods of Tribess et al. [25] and Zhang and Hamaker [26] with slight modification. A total of $3 \mathrm{mg}$ of UBF (dry weight basis) was weighed to an aluminum pan and $9 \mu \mathrm{L}$ of distilled water added to the pan. The pan containing the sample was hermitically sealed with a universal crimper press (Perkin-Elmer, Shelton, CT, USA) and samples were allowed to equilibrate for $1 \mathrm{~h}$ prior to testing. A standard reference empty aluminum pan was used as reference. Heating rate of sample was $10{ }^{\circ} \mathrm{C} / \mathrm{min}$ at a heating programme of $25-120^{\circ} \mathrm{C}$. Thermal transitions of samples for gelatinization were characterized by To (onset temperature), $T p$ (peak temperature), $T c$ (conclusion temperature) and $\Delta H$ (enthalpy of gelatinization). Samples were analyzed in triplicate and Pyris software (Perkin-Elmer, Shelton, CT, USA) was used for calculation of obtained data.

\section{Statistical analysis}

Results of experiment were statistically analyzed for analysis of variance (ANOVA) using SPSS 22 for windows (SPSS Inc., Chicago, IL). ANOVA was performed on values with means of obtained results separated using Duncan Multiple Comparison Test [27]. 


\section{Results and discussion}

\section{Effects of pretreatment on colour profile of UBF}

The appearance of a product as judged by its colour, can be used as a determinant of the pigment content of the product. This according to Francis [28], is often used as a quality index of the produce. Food produce are also evaluated for quality by consumers through their appearance [29]. Upon pretreatment of banana samples with ascorbic, citric and lactic acid and at different concentrations, the $L * a * b *$ values obtained varied significantly $(p<0.05)$ in UBF of all cultivars examined. Colour variations were observed in both the non-commercial and commercial (Williams) pretreated UBF. Compared to pretreated UBF of non-commercial cultivars, the $L^{*}$ values of commercial Williams were the least: $76.36-78.82$ in all pretreatment concentration (Table 1). Conversely, the $b^{*}$ values for pretreated Williams UBF was higher than the non-commercial cultivars across all pretreatment concentration. Occurrence of low lightness and high yellowness values in organic acid pretreated Williams UBF can be attributed to the increased activity of the enzyme polyphenol oxidase (PPO) in the commercial cultivar examined.

As stated by Alkarkhi et al. [7] the action of PPO in the pulp and peel of both ripe and unripe banana fruit leads to enzymatic browning. PPO activity is further increased upon exposure of fruit pulp to oxygen during removal of peel and drying of pulp. The resultant effect is the formation of the brown by-product which brings about the unpleasant browning of the flour. Therefore high lightness values recorded in flour especially in the non-commercial cultivars shows the effect of organic acid pretreatment in mitigating enzymatic browning caused by the action of PPO.

\section{Effects of pretreatment on whiteness and browning index of UBF}

The WI of flour obtained from commercial banana Williams, was significantly low when compared to values obtained from the non-commercial cultivars. The effect of pretreatment on WI of UBF was more observed in Luvhele and Muomva-red non-commercial banana cultivars as WI obtained from these cultivars were significantly higher than those of Mabonde and Williams (Fig. 1). White colour of flour is a critical factor in determining consumers' preference in purchase and consumption of flour products. WI specifies whiteness of a food produce and indicates the level of discolouration during processing [5]. Result of this study shows that discolouration was more observed in commercial Williams UBF upon organic acid pretreatment and drying of the cultivar. Pretreatment at different concentrations and drying had greater effect in reducing the level of discolouration in the non-commercial banana cultivars.

Browning index (BI) was obtained from the $L^{*} a * b^{*}$ values with results varying according to pretreatment. BI is used to determine total colour change as a result of browning of food produce [29, 30]. Apart from polyphenol oxidase activity of fruits which is a method that determines enzymatic browning in food produce, BI can be used as a physical method of determining browning in processed foods through the use of $L^{*} a * b *$ values obtained from the Hunterlab colour scale [29]. Results of experiment conducted and obtained from $L * a * b *$ shows that pretreatment reduced browning in all UBF obtained from different cultivars. Citric acid pretreatment of Mabonde UBF (10 g/L) showed the least BI in all samples analysed. The commercial Williams UBF had the highest BI at ascorbic acid pretreatment of $20 \mathrm{~g} / \mathrm{L}$ when compared to UBF obtained from other cultivars (Fig. 2). Results obtained for BI is similar to results obtained by Mohapatra et al. [22] who investigated the postharvest hardness and colour evolution of white button Mushrooms (Agaricus bisporus). According to the authors, storage temperature had effect on the BI of stored mushroom as the BI of mushrooms increased with increase in storage temperature. Generally pretreatment had a greater effect in reducing browning of UBF obtained from non-commercial banana cultivars than UBF from commercial UBF. Hence, non-commercial UBF had brighter colour appearance than UBF of commercial banana.

\section{Effects of pretreatment on bulk density of UBF}

Result of organic acid pretreatment on bulk density of UBF samples shows varying effects on individual banana cultivars. Bulk density of all UBF examined at different pretreatment concentration was generally high (0.66-0.84 $\mathrm{g} \mathrm{m} / \mathrm{L})$. There was significant difference in bulk density of all UBF from different cultivars across all pretreatment concentration. Bulk density of UBF was highest at $0.84 \mathrm{~g} \mathrm{~m} / \mathrm{L}$ for Williams UBF at ascorbic acid pretreatment concentration of $10 \mathrm{~g} / \mathrm{L}$ while Luvhele had the lowest bulk density of $0.66 \mathrm{~g} \mathrm{~m} / \mathrm{L}$ at lactic acid pretreatment concentration of $15 \mathrm{~g} / \mathrm{L}$ (Fig. 3). The result shows that bulk density of UBF obtained from commercial banana cultivar was higher than bulk density obtained from UBF of all non-commercial cultivars. This could be attributed to the higher mass per volume of the commercial bananas used in this research when compared to the non-commercial bananas. Commercial banana had longer fruit length and bigger fruit girth when compared to all the non-com- 


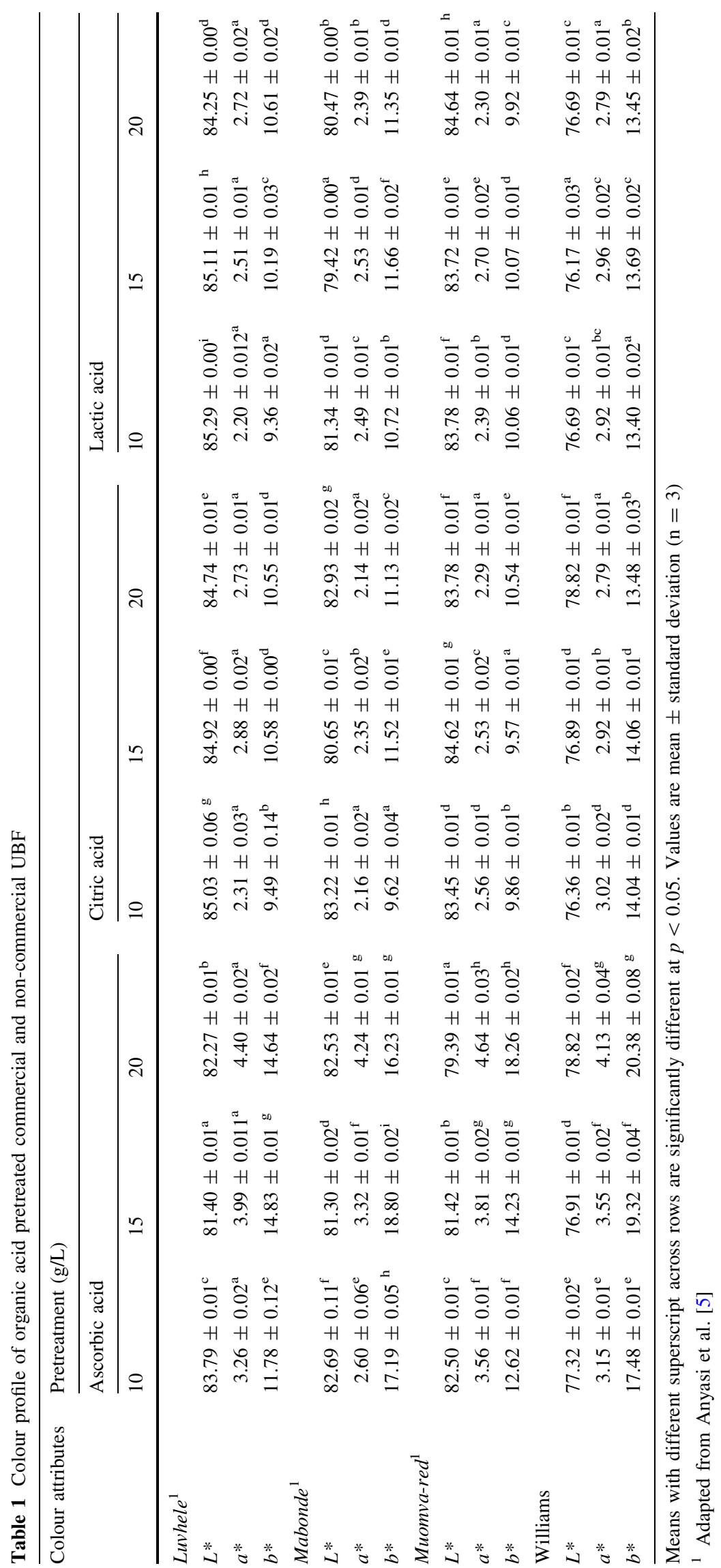




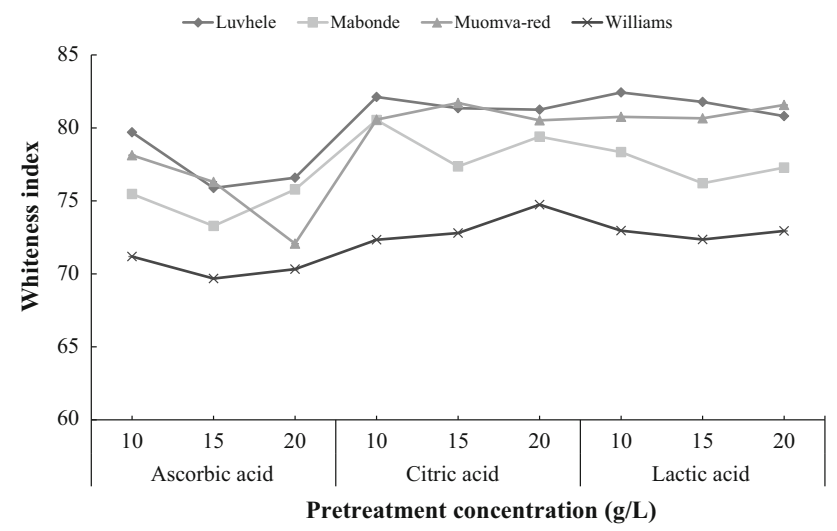

Fig. 1 Whiteness index of ascorbic, citric and lactic acid pretreated commercial and non-commercial UBF

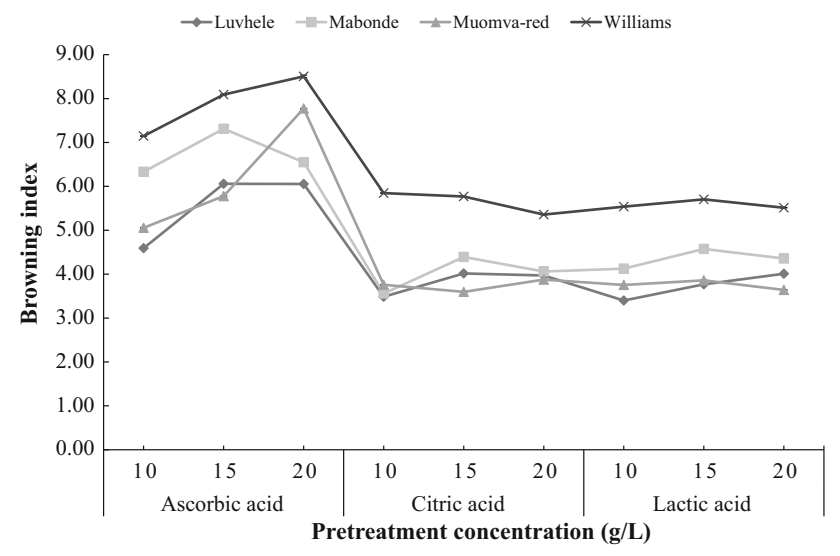

Fig. 2 Browning index of ascorbic, citric and lactic acid pretreated commercial and non-commercial UBF mercial cultivars used in this research. Bulk density is a measure of heaviness of a flour sample [24]. It is a property that determines the weight of packaged goods especially flour produce. This helps in proper packing, loading and transporting of packaged materials from one location to another. The result also implies a greater mass in packaging of all UBF used in this analysis as there was generally a high mass per volume of all the UBF examined.

\section{Effects of pretreatment on swelling power of UBF}

The ability of starch to entrain water and provide a sink for water expressed by changes in the food produce can be determined by measuring the swelling power which is different from syneresis that ensues when water is expelled from within the swollen starch granules or by other ingredients [19]. Swelling power was within the range of $8.30-12.76 \mathrm{~g} / \mathrm{g}$ in all cultivars examined. There was no significant difference $(p<0.05)$ in swelling power of UBF obtained from Luvhele cultivar across all pretreatment concentration. Significant difference was recorded in swelling power of Mabonde, Muomva-red and Williams UBF. Swelling power was significantly different and highest for Muomva-red (13.02 g/g) at lactic acid pretreatment concentration of $10 \mathrm{~g} / \mathrm{L}$. Luvhele UBF, however, recorded the lowest swelling power of $8.30 \mathrm{~g} / \mathrm{g}$ at lactic acid pretreatment concentration of $10 \mathrm{~g} / \mathrm{L}$ among all cultivars examined (Fig. 4). The swelling power of flour and starch granules of different food products has been shown to correlate positively with increase in temperature [31]. In an experiment conducted by De la Torre-Guitierrez et al.
Fig. 3 Bulk density of ascorbic, citric and lactic acid pretreated commercial and noncommercial UBF. Error bars are $\mathrm{SE}$ of mean values $(\mathrm{n}=3)$

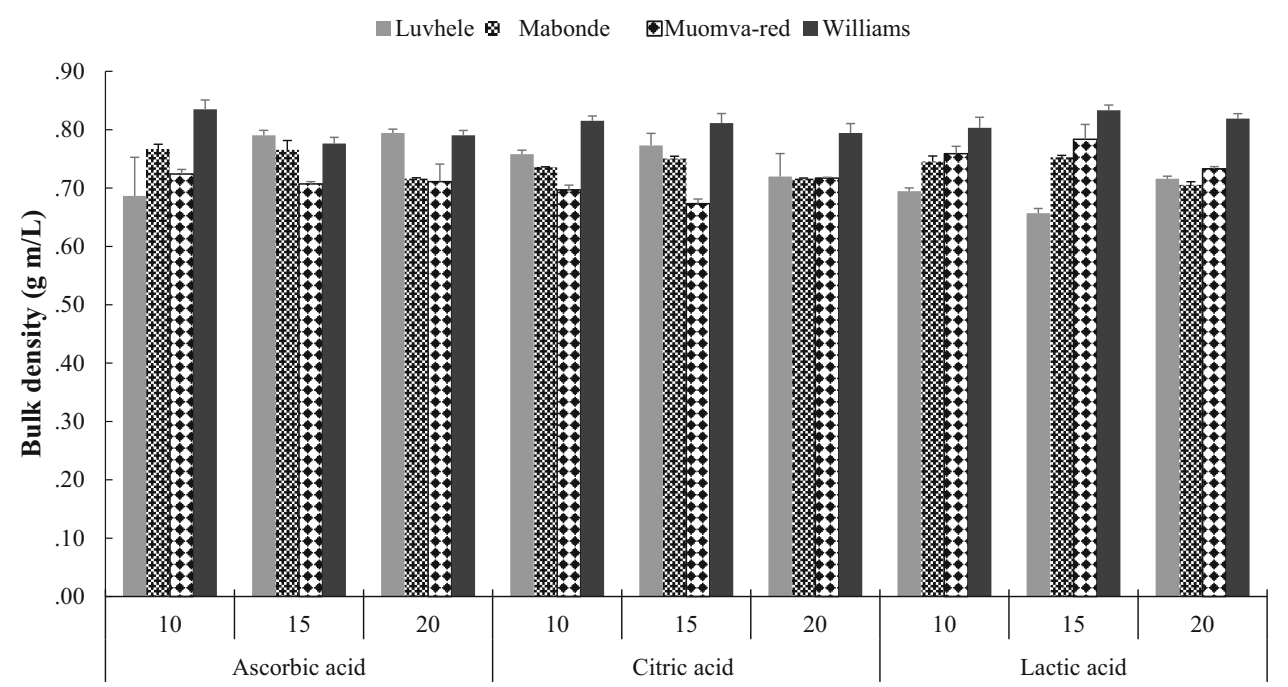

Pretreatment concentration $(\mathrm{g} / \mathrm{L})$ 
Fig. 4 Swelling power of ascorbic, citric and lactic acid pretreated commercial and noncommercial UBF. Error bars are SE of mean values $(\mathrm{n}=3)$

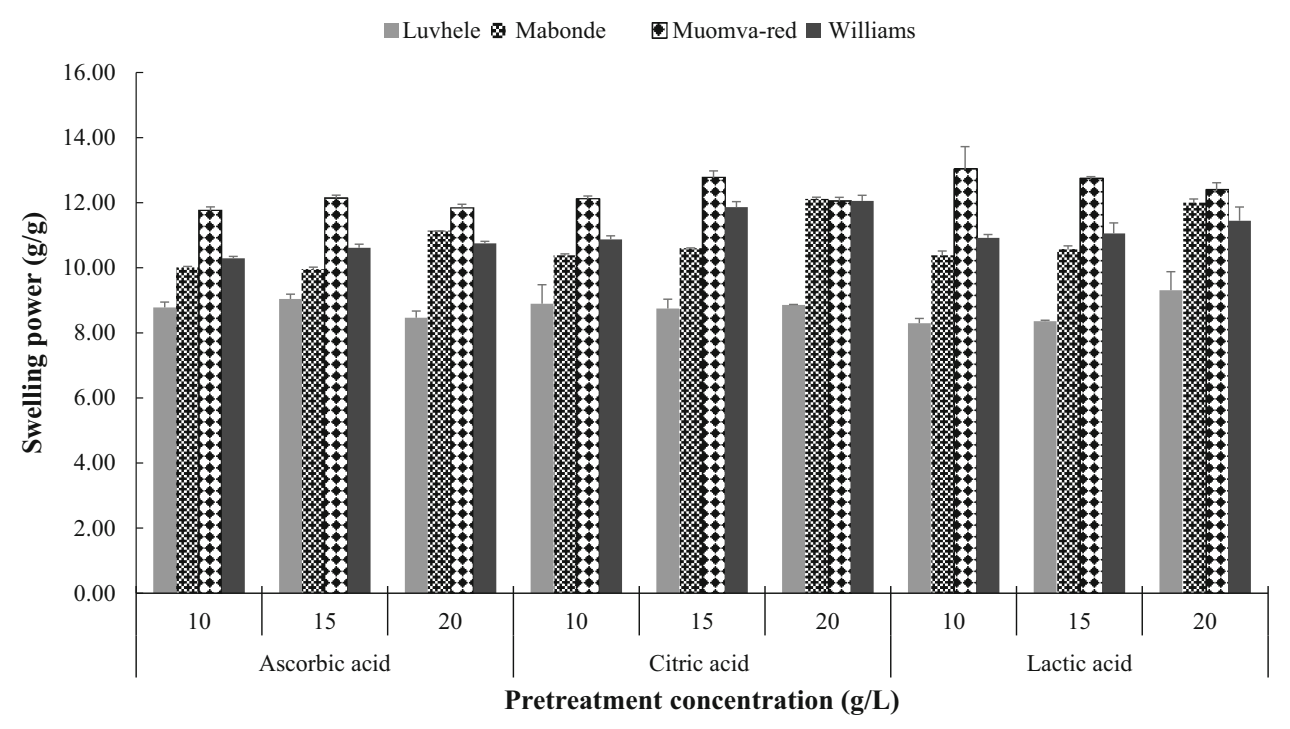

[31] to determine the functional properties of square banana starch, the swelling power of the banana starch began to swell rapidly at temperatures above $70^{\circ} \mathrm{C}$. The occurrence of swelling in flour and starch granules at elevated temperatures of above $70{ }^{\circ} \mathrm{C}$ can be attributed to the breaking down of intermolecular hydrogen bonds in amorphous regions thereby allowing for the absorption of water.

\section{Effects of pretreatment on water solubility index of UBF}

WSI results for all cultivars were generally low with Mabonde and Muomva-red recording low WSI values of 0.009 and $0.010 \mathrm{~g} / \mathrm{g}$ at $10 \mathrm{~g} / \mathrm{L}$ of citric acid pretreatment for UBF (Fig. 5). There was no significant difference in WSI of all commercial and non-commercial UBF except

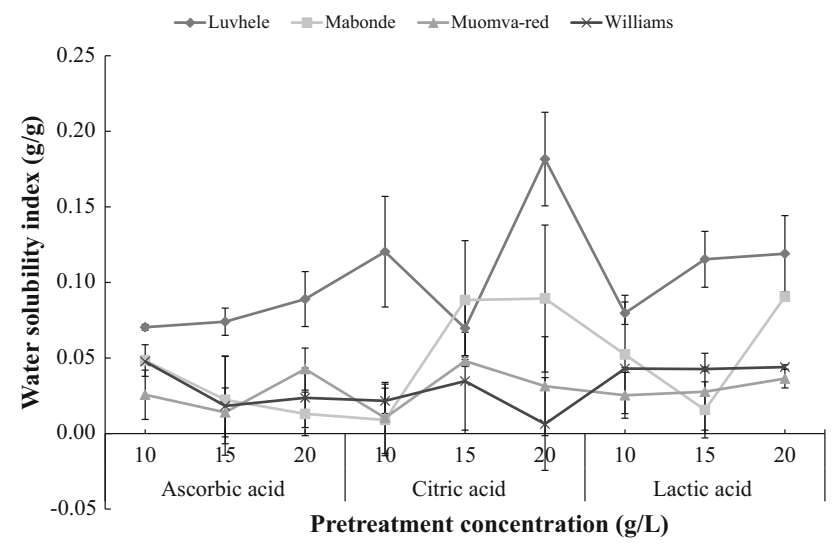

Fig. 5 Water solubility index of ascorbic, citric and lactic acid pretreated commercial and non-commercial UBF. Error bars are SE of mean values $(\mathrm{n}=3)$ for UBF of Mabonde cultivar while WSI was highest for Luvhele $(0.18 \mathrm{~g} / \mathrm{g})$ at citric acid pretreatment of $20 \mathrm{~g} / \mathrm{L}$ respectively. According to Mariotti et al. [32] native starches are naturally insoluble in water, though their solubility can be greatly improved, upon cooking of the starch. Thus, generally low WSI values recorded for all UBF of different cultivars can be attributed to the high starch content of UBF used in this study. The high starch content present in flour is as a result of the state of unripeness of the banana cultivars used in the processing of the flour. Banana cultivars used in this analysis were obtained at unripe green stage 2 of maturity [20].

According to Zhang et al. [1], swelling power and WSI offer evidence of the degree of interaction between starch chains within the amorphous and crystalline domains of granules obtained from fruit flour and starch. The degree of this interaction is affected by the ratio of amylose to amylopectin and by the molecular weight distribution and bond characteristics of amylose and amylopectin.

\section{Effects of pretreatment on microstructure of UBF}

Surface morphology of flour from the SEM of all four cultivars showed marked variations in structure, shape and size of starch granules of the different banana flour. Food microstructures are affected by food processing activities such as heating, freezing, milling, baking, comminuting, emulsions and in the mouth prior to swallowing [14]. These processing activities lead to the corresponding changes in food microstructure with the concomitant effects on the texture, flavour, shelf life, nutritional properties and overall quality of the food produce. Microstructures from electron micrographs suggest that granules were considerably irregular in their structures among all four cultivars upon pretreatment with ascorbic, citric and lactic acid. Observed 

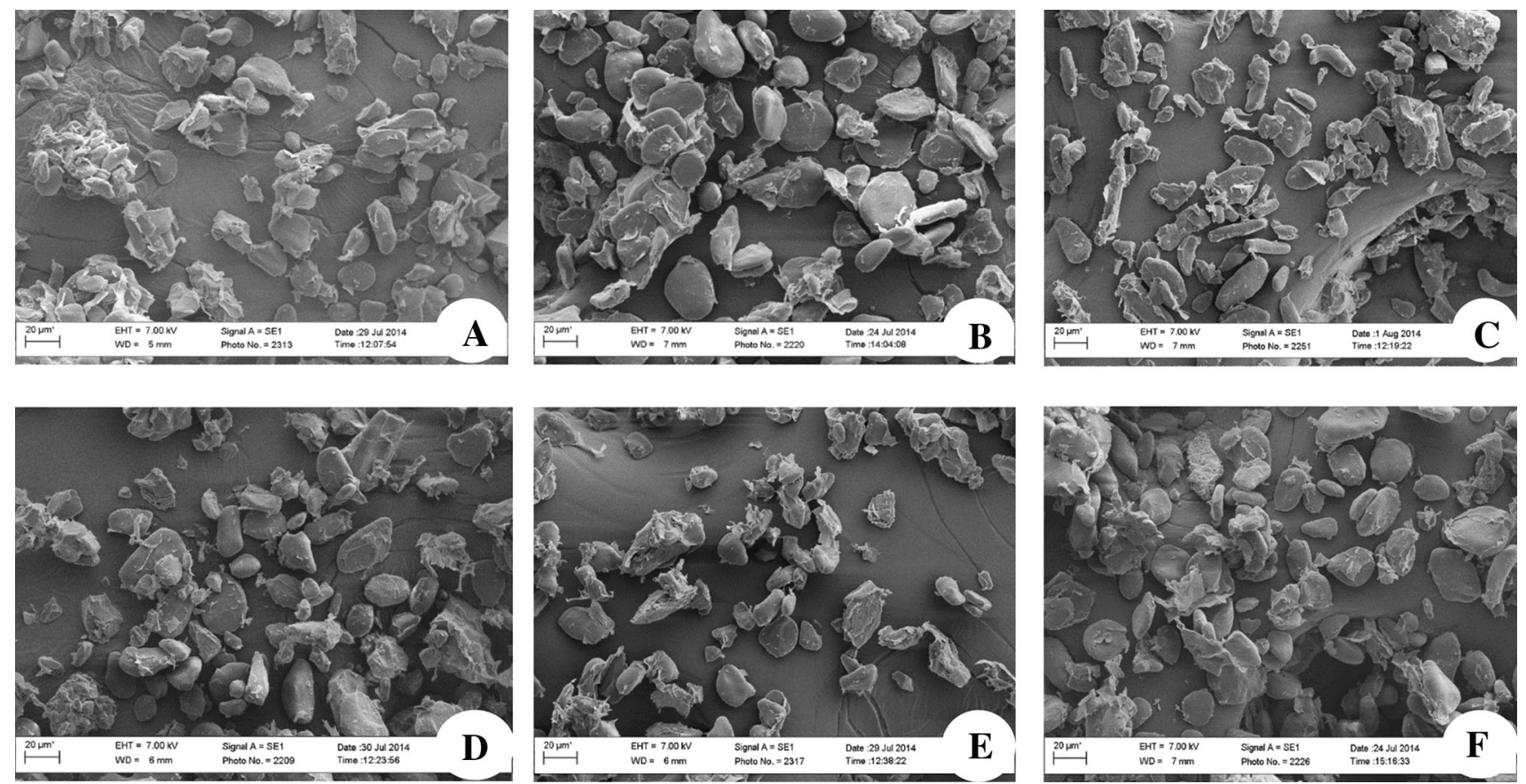

Fig. 6 Microstructure of flour obtained from ascorbic acid (10 g/L) pretreated unripe banana cultivars: a, Luvhele; b, Mabonde; c, Muomva-red; d, Williams; and citric acid $(10 \mathrm{~g} / \mathrm{L})$ pretreated unripe banana cultivars: e, Luvhele; f, Mabonde. Scale bar $=20 \mu \mathrm{m}$ at magnification of $\times 1000$
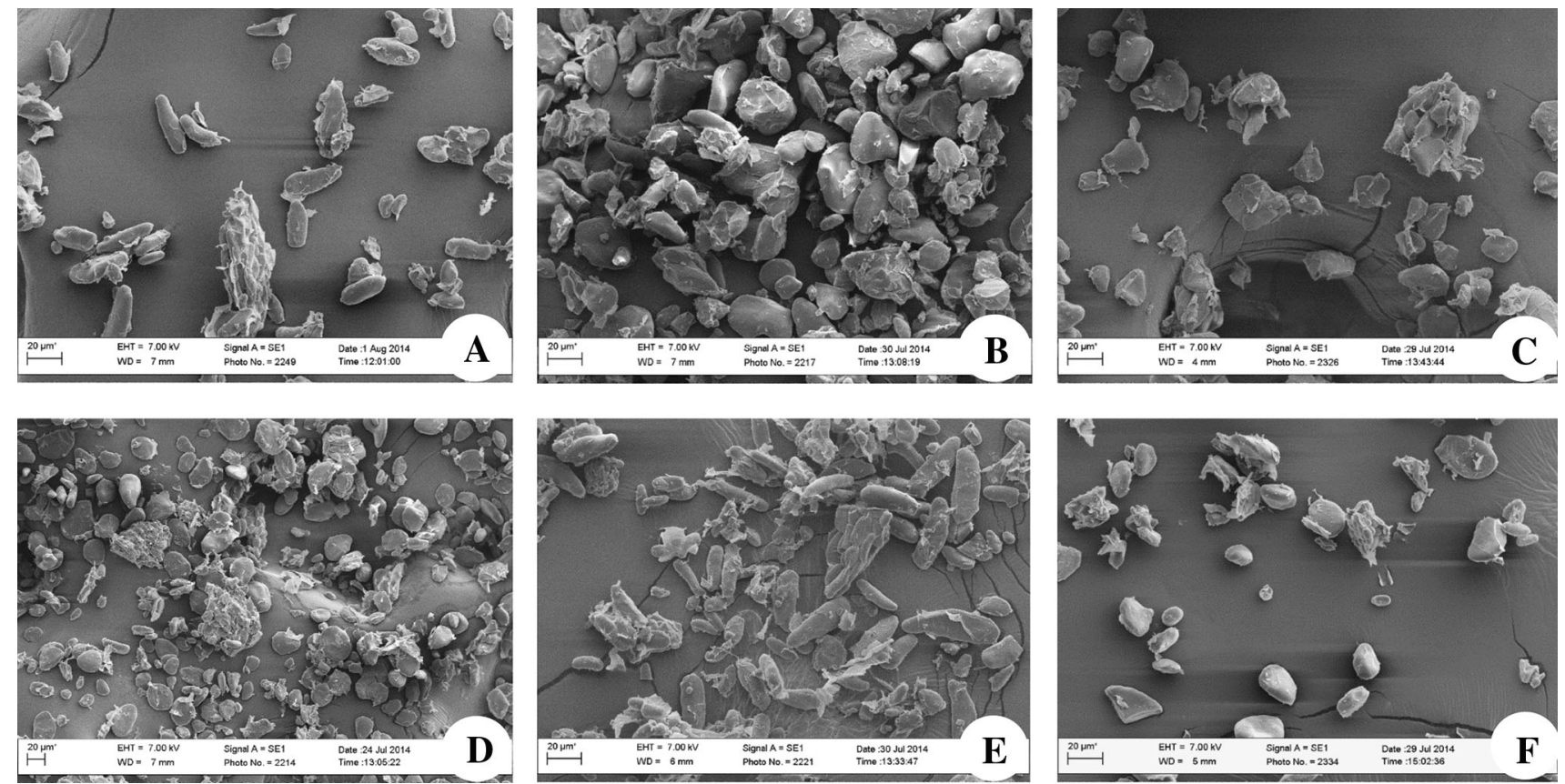

Fig. 7 Microstructure of flour obtained from citric acid (10 g/L) pretreated unripe banana cultivars. a, Muomva-red; b, Williams; and lactic acid $(10 \mathrm{~g} / \mathrm{L})$ pretreated unripe banana cultivars: c, Luvhele; d, Mabonde; $\mathbf{e}$, Muomva-red; $\mathbf{f}$, Williams. Scale bar $=20 \mu \mathrm{m}$ at magnification of $1000 \times$

shapes include polygonal for Luvhele, oval for Mabonde, elongated for Muomva-red and between polygonal and spherical for Williams unripe banana flour (Figs. 6,7). Oval shape of granules obtained from unripe Mabonde flour were similar to those obtained in the works of Utrilla-Coello et al.
[33] which showed starch granules exhibiting regular shapes with oval appearance. Drying temperature of $70{ }^{\circ} \mathrm{C}$ for $12 \mathrm{~h}$ during flour production as well as differences in cultivar $[15,16]$ however had an effect on the shape of observed granules and accounted for the variations in granule 
morphology amongst the different cultivars. Irregular shapes and size of granules as obtained from SEM could be attributed to high heat treatment leading to irreversible swelling, puncturing and gelatinization of banana flour.

Upon pretreatment with GRAS organic acids of individual cultivars, there was no difference in shape and structure of granules obtained from flour. Pretreatment had no effect on the shape as all cultivars retained their size and shape. Muomva-red cultivar still exhibited elongated shape while Mabonde cultivar also exhibited oval shape in all pretreatment concentration. Swelling of flour granules resulting in gelatinization and loss of birefringence was also observed in all pretreated cultivars, though this has been attributed to oven drying temperature of $70{ }^{\circ} \mathrm{C}$ (for $12 \mathrm{~h}$ ) used in processing of flour. Adhesion between granules was also observed in flour samples of all cultivars irrespective of pretreatment concentration. This result was similar to the one obtained by Wang and Copeland [34] on the effects of alkali treatment on structure and function of pea starch granules. Presence of adhesion between granules can be attributed to the occurrence of lipid and protein molecules in the granules of unripe flour samples [18].

\section{Effects of pretreatment on thermal properties of UBF}

Results of DSC analysis showed curves of single endothermic transition for all UBF at various concentrations of organic acid pretreatment. From the results of the experiment, the onset temperature (To) range from 49.82 to $65.59^{\circ} \mathrm{C}$, peak temperature (Tp) from 60.11 to $76.71{ }^{\circ} \mathrm{C}$, conclusion temperature (Tc) from 70.36 to $94.16{ }^{\circ} \mathrm{C}$ and enthalpy of gelatinization $(\Delta H)$ from 2.61 to $32.24 \mathrm{~J} / \mathrm{g}$ (Table 2). Significant difference $(p<0.05)$ was recorde$\mathrm{d}$ in $T o$ of all cultivars as affected by organic acid pretreatment except for Williams cultivar. No significant difference was observed in To of Williams UBF across pretreatment. Similar result was also observed in $T p$ and $T c$ for Williams $\mathrm{UBF}$ as there was no significant difference in these values. Likewise, there was no significant difference for $T c$ and $\Delta H$ of Luvhele UBF across pretreatment. Conversely, Mabonde and Muomva-red showed significant differences in the $T o, T c, T p$ and $\Delta H$ of all UBF examined at various pretreatment concentrations. The $T p$ of Luvhele UBF was significantly highest at $76.71{ }^{\circ} \mathrm{C}$ for lactic acid pretreatment concentration of $10 \mathrm{~g} / \mathrm{L}$ and among all cultivars examined while Mabonde UBF Tp was significantly lowest at $60.11{ }^{\circ} \mathrm{C}$ and at lactic acid pretreatment of $10 \mathrm{~g} / \mathrm{L} . \Delta H$ of Mabonde UBF was significantly lowest at $2.61 \mathrm{~J} / \mathrm{g}$ at ascorbic acid pretreatment of $20 \mathrm{~g} / \mathrm{L}$ across pretreatment and among all cultivars while $\Delta H$ of Muomva-red was significantly highest $32.24 \mathrm{~J} / \mathrm{g}$ at citric acid pretreatment of $20 \mathrm{~g} / \mathrm{L}$.
According to Mason [19], gelatinization is the disruption or collapse of molecular order within the starch granule manifested in irreversible changes in properties such as granular swelling, native crystallite melting, loss of birefringence and starch solubilisation. DSC therefore measures the amount of energy required to reduce the order present in starch in the food sample [35]. Occurrence of initial gelatinization and its range is influenced by factors such as starch concentration, method of observation, granule type and heterogeneities within the granule population being observed [19]. The $T o, T p, T c$ and $\Delta H$ values obtained in this study are within the range of results obtained in studies done on other banana cultivars as reported by Bello-Perez et al. [36], Tribess et al. [25] and Reddy et al. [37]. Low transition temperatures and $\Delta H$ values recorded in UBF samples have been attributed to abundance of short amylopectin chains present in the starch of samples examined $[25,37]$ while slightly higher transition temperature values in UBF have been attributed to the contribution of heat-moisture treatment rather than organic acid treatment used in this study [38].

\section{Conclusion}

Organic acid pretreatment mitigated the browning effect of discolouration of banana flour obtained from all cultivars, thus increasing the utilization and application of UBF in food based products and processes. Bulk density of UBF was consistent with values of flour obtained from other plant produce with its positive effect on the packaging and transportation of flour. Organic acid pretreatment had no observable effect on thermal properties of UBF. Conversely, transition temperatures and flour gelatinization properties of UBF were affected majorly by heat treatment and drying time of samples. Solubility and swelling properties of UBF were also reportedly low due to the production of flour at temperature of $70{ }^{\circ} \mathrm{C}$. Internal microstructures obtained from SEM micrographs showed variations in shapes and size of flour granules of all four cultivars when subjected to heat treatment of $70{ }^{\circ} \mathrm{C}$. Pretreatment with GRAS organic acids had little or no effect on shapes of flour granules though gelatinization of starch granules also led to loss of crystallinity and birefringence. Hence, the effect of heat treatment in terms of pore formation and rupturing of starch granules in UBF can further be investigated. Use of pretreatment in flour production will therefore enhance the application of banana flour in commercial utilization and product formulations due to its minimal effect in the functional, thermal properties and internal structure of the flour. 


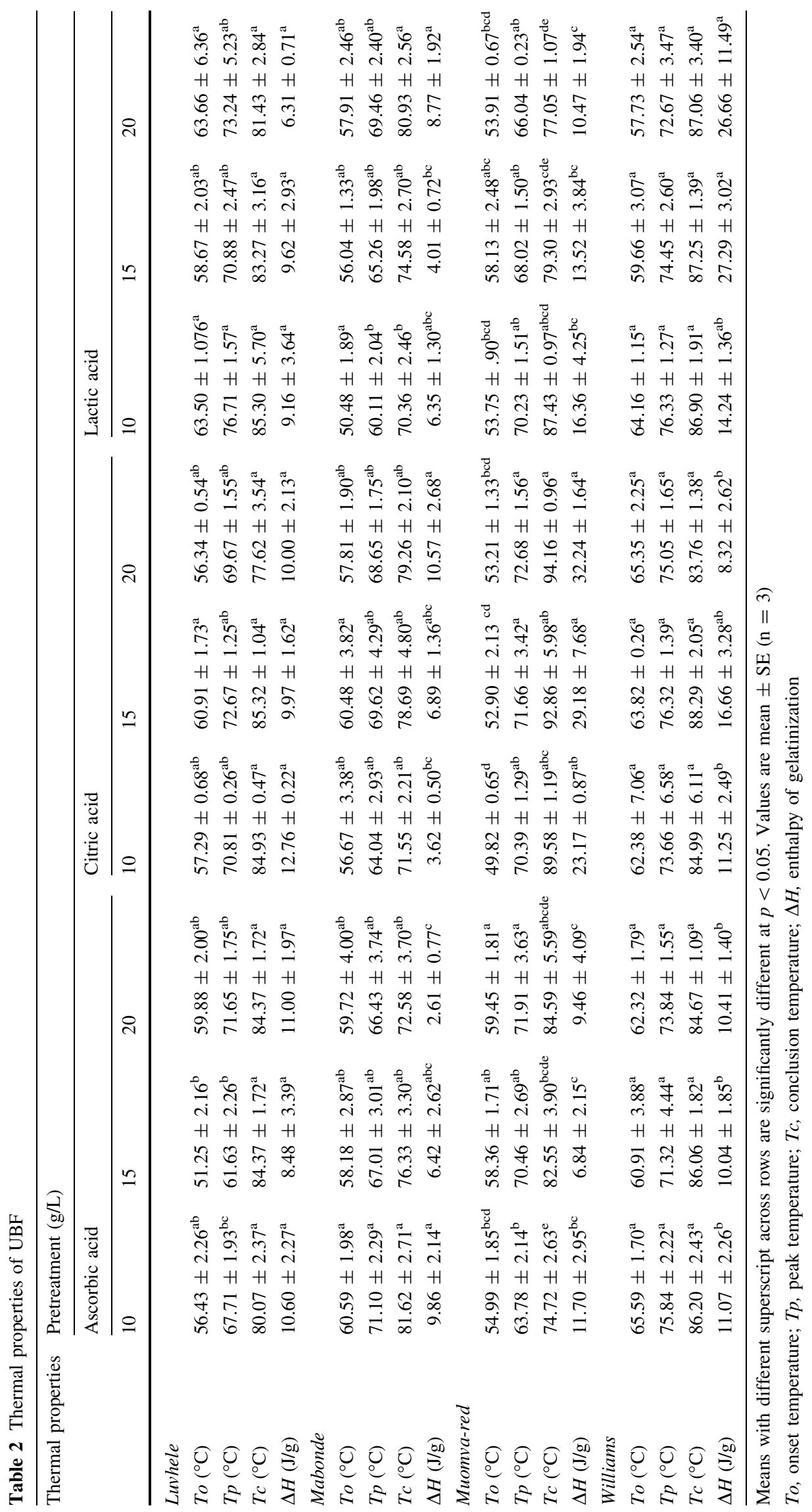


Acknowledgments The authors wish to acknowledge the financial contributions and support to TAA from the University of Venda (Univen) Research and Publication Committee Fund (SARDF/13/ FST/01) and the Work Study Programme of the Univen, South Africa.

Open Access This article is distributed under the terms of the Creative Commons Attribution 4.0 International License (http://creative commons.org/licenses/by/4.0/), which permits unrestricted use, distribution, and reproduction in any medium, provided you give appropriate credit to the original author(s) and the source, provide a link to the Creative Commons license, and indicate if changes were made.

\section{References}

1. P. Zhang, R.L. Whistler, J.N. Bemiller, B.R. Hamaker, Banana starch: production, physicochemical properties, and digestibility - a review. Carbohydr. Polym. 59, 443-458 (2005)

2. T.A. Anyasi, A.I.O. Jideani, G.R.A. Mchau, Functional properties and postharvest utilization of commercial and noncommercial banana cultivars. Compr. Rev. Food. Sci. Food. Safe. 12(5), 509-522 (2013)

3. A.M. Langkilde, M. Champ, H. Andersson, Effects of high-resistant-starch banana flour (RS2) on in vitro fermentation and the small-bowel excretion of energy, nutrients, and sterols: an ileostomy study. Am. J. Clin. Nutr. 75, 104-111 (2002)

4. L.A. Bello-Perez, E. Agama-Acevedo, P. Osorio-Diaz, R.G. Utrilla-Coello, F.J. Garcia-Suarez, Banana and Mango Flours, in Flour and Breads and their Fortification in Health and Disease Prevention, ed. by V.R. Preedy, R.R. Watson, V.B. Patel (Academic Press, San Diego, 2011), pp. 235-245

5. T.A. Anyasi, A.I.O. Jideani, G.R.A. Mchau, Effect of organic acid pretreatment on some physical, functional and antioxidant properties of flour obtained from three unripe banana cultivars. Food. Chem. 172, 515-522 (2015)

6. M.M. Theron, J.F.R. Lues, Organic acids and food preservation (CRC Press, Boca Raton, 2011), p. 340

7. A.F.M. Alkarkhi, S. Ramli, Y.S. Yong, A.M. Easa, Comparing physicochemical properties of banana pulp and peel flours prepared from green and ripe fruits. Food. Chem. 129, 312-318 (2011)

8. S. Wang, T. Lin, G. Man, H. Li, L. Zhao, J. Wu, X. Liao, Effects of anti-browning combinations of ascorbic acid, citric acid, nitrogen and carbon dioxide on the quality of banana smoothies. Food. Bioprocess. Technol. 7, 161-173 (2014)

9. M.K. Nielsen, N. Arneborg, The effect of citric acid and $\mathrm{pH}$ on growth and metabolism of anaerobic Saccharomyces cerevisiae and Zygosaccharomyces bailii cultures. Food. Microbiol. 24, 101-105 (2007)

10. E. Juarez-Garcia, E. Agama-Acevedo, S.G. Sayago-Ayerdi, S.L. Rodriguez-Ambriz, A. Bello-Perez, Composition, digestibility and application in bread making of banana flour. Plant. Food. Hum. Nutr. 61, 131-137 (2006)

11. L.L. Niba, Carbohydrates: Starch, in Handbook of Food Science, Technology and Engineering, vol. I, ed. by Y.H. Hui, J.D. Culbertson, S. Duncan, I. Guerrero-Legarreta, E.C.Y. Li-Chan, C.Y. Ma, C.H. Manley, T.A. McMeekin, W.K. Nip, L.M.L. Nollet, M.S. Rahman, F. Toldra, Y.L. Xiong (CRC Press, Boca Raton, 2006), p. 3

12. J.M. Aguilera, D.W. Stanley, Microstructural Principles of Food Processing and Engineering, 2nd edn. (Aspen Publishers, Maryland, 1999), pp. 185-249

13. H. Dogan, B. Subramanyam, J. Pedersen, Analysis for extraneous matter, in Food Analysis, ed. by S.S. Nielsen (Springer Science + Business Media, New York, 2010), pp. 351-365
14. J.M. Aguilera, P. Bouchon, Scanning electron and transmission electron microscopies in food analysis, in Handbook of Food Analysis Instruments, ed. by By S. Otles (CRC Press, Boca Raton, 2009), pp. 495-511

15. M.N. Sivak, J. Preiss, Advances in food and nutrition research. Starch: Basic science to biotechnology. (Academic Press, San Diego, California, 1998), pp. 217

16. D.S. Jackson, Starch, in Encyclopedia of Food Science and Nutrition, ed. by B. Caballero, L. Trugo, P. Finglas (Academic Press, San Diego, 2003), pp. 5561-5576

17. J. Jane, Structural features of starch granules II, in Starch: Chemistry and Technology, 3rd edn., ed. by J.N. BeMiller, R.L. Whistler (Academic Press, Elsevier, Burlington, 2009), pp. 193-236

18. S. Perez, P.M. Baldwin, D.J. Gallant, Structural features of starch granules I, in Starch: Chemistry and Technology, 3rd edn., ed. by J.N. BeMiller, R.L. Whistler (Academic Press, Elsevier, Burlington, 2009), pp. 149-192

19. W.R. Mason, Starch Use in Foods, in Starch: Chemistry and Technology, 3rd edn., ed. by J.N. BeMiller, R.L. Whistler (Academic Press, Elsevier, Burlington, 2009), pp. 750-755

20. G. Aurore, B. Parfait, L. Fahrasmane, Bananas, raw materials for making processed food products. Trends. Food. Sci. Technol. 20, 78-91 (2009)

21. R. Rodriguez-Aguilera, J.C. Oliveira, J.C. Montanez, P.V. Mahajan, Effect of modified atmosphere packaging on quality factors and shelf-life of surface mould ripened cheese: part I constant temperature. LWT. Food. Sci. Technol. 44, 330-336 (2011)

22. D. Mohapatra, Z.M. Bira, J.P. Kerry, J.M. Frias, F.A. Rodrigues, Postharvest hardness and color evolution of white button mushrooms (Agaricus bisporus). J. Food. Sci. 75(3), E146-E152 (2010)

23. R. Krishnan, U. Dharmaraj, R.S. Manohar, N.G. Malleshi, Quality characteristics of biscuits prepared from finger millet seed coat based composite flour. Food. Chem. 129, 499-506 (2011)

24. A.K. Oladele, J.O. Aina, Chemical composition and functional properties of flour produced from two varieties of tigernut (Cyperus esculentus). African J. Biotechnol. 6(21), 2473-2476 (2007)

25. T.B. Tribess, J.P. Hernandez-Uribe, M.G.C. Mendez-Montealvo, E.W. Menezes, L.A. Bello-Perez, C.C. Tadini, Thermal properties and resistant starch content of green banana flour (Musa cavendishii) produced at different drying conditions. LWT. Food. Sci. Technol. 42, 1022-1025 (2009)

26. P. Zhang, B.R. Hamaker, Banana starch structure and digestibility. Carbohydr. Polym. 87, 1552-1558 (2012)

27. G. Gamst, L.S. Meyers, A.J. Guarino, Analysis of Variance Designs: A Conceptual and Computational Approach with SPSS and SAS (Cambridge University Press, New York, 2008), pp. 247-286

28. F.J. Francis, Quality as influenced by color. Food. Qual. Prefer. 6(3), 149-155 (1995)

29. P.B. Pathare, U.L. Opara, F.A. Al-Said, Colour measurement and analysis in fresh and processed foods: a review. Food Bioprocess Technol. 6, 36-60 (2013)

30. L.J. Quitão-Teixeira, I. Aguiló-Aguayo, A.M. Ramos, O. MartínBelloso, Inactivation of oxidative enzymes by high intensity pulsed electric field for retention of color in carrot juice. Food. Bioprocess. Technol. 1(4), 364-373 (2008)

31. L. De La Torre-Gutierrez, L.A. Chel-Guerrero, D. BetancurAncona, Functional properties of square banana (Musa balbisiana) starch. Food. Chem. 106, 1138-1144 (2008)

32. M. Mariotti, C. Alamprese, M.A. Pagani, M. Lucisano, Effect of puffing on ultrastructure and physical characteristics of cereal grains and flours. J. Cereal. Sci. 43, 47-56 (2006) 
33. R.G. Utrilla-Coello, M.E. Rodriguez-Huezo, H. Carrillo-Navas, C. Hernandez-Jaimes, E.J. Vernon-Carter, J. Alvarez-Ramirez, In vitro digestibility, physicochemical, thermal and rheological properties of banana starches. Carbohydr. Polym. 101, 154-162 (2014)

34. S. Wang, L. Copeland, Effect of alkali treatment on structure and function of pea starch granules. Food. Chem. 135, 1635-1642 (2012)

35. H. Jiang, Y. Zhang, Y. Hong, Y. Bi, Z. Gu, L. Cheng, Z. Li, C. Li, Digestibility and changes to structural characteristics of green banana starch during in vitro digestion. Food. Hydrocolloid. 49, 192-199 (2015)

36. L.A. Bello-Perez, E. Agama-Acevedo, S.G. Sayago-Ayerdi, E. Moreno-Damian, Some structural, physicochemical and functional studies of banana starches isolated from two varieties growing in Guerrero. Mexico. Starch/Starke. 52(2-3), 68-73 (2000)

37. C.K. Reddy, S. Haripriya, P.V. Vidya, Morphology, physicochemical and functional characteristics of starches from different banana cultivars. J. Food. Sci. Technol. 52(11), 7289-7296 (2015)

38. A.-C. Eliasson, M. Gudmundsson, Starch: Physicochemical and Functional Aspects, in Carbohydrates in Food, 2nd edn., ed. by A.-C. Eliasson (CRC Press, Boca Raton, 2006), pp. 411-415 